\title{
PENGARUH PEMANGKASAN PUCUK DAN PEMBERIAN DOSIS PUPUK AZOLLA PINNATA TERHADAP PERTUMBUHAN DAN HASIL UBI JALAR UNGU (Ipomoea batatas blackie)
}

\author{
Adi Guntoro $^{1 *}$ Priyono $^{2}$ Saiful Bahri ${ }^{2}$ \\ ${ }^{1}$ Mahasiswa program S1 Agroteknologi, Fakultas Pertanian, Universitas Slamet Riyadi. \\ ${ }^{2}$ Staf Pengajar Program Studi Agroteknologi, Fakultas Pertanian, Universitas Slamet Riyadi \\ 1*guntoroadi94@gmail.com
}

\begin{abstract}
ABSTRAK
Penelitian tentang "Pengaruh pemangkasan pucuk dan pemberian dosis pupuk kompos Azolla pinnata (Ipomea batatas blackie.)" telah dilaksanakan mulai tanggal 12 Oktober 2018 sampai 18 Januari 2019 Randusari RT 02 RW 01, Slogohimo, Wonogiri. Penelitian ini bertujuan untuk (1) mengetahui pengaruh dari pemangkasan pucuk terhadap pertumbuhan dan hasil ubi jalar ungu (Ipomoea batatas blackie.), (2) mengetahui pengaruh dari pemberian dosis pupuk kompos Azolla pinnata terhadap pertumbuhan dan hasil ubi jalar (Ipomoea batatas blackie.), (3) mengetahui pengaruh terbaik dari pemangkasan pucuk dan pemberian dosis pupuk kompos Azolla pinnata terhadap pertumbuhan dan hasil ubi jalar ungu (Ipomoea batatas blackie.) Penelitian menggunakan Rancangan Acak Kelompok Lengkap (RAKL) yang disusun secara faktorial. Perlakuan terdiri dari 2 faktor, masing-masing kombinasi perlakuan diulang 3 kali. Adapun kedua faktor tersebut adalah : (1)pemangkasan pucuk (P) dengan 3 (tiga) taraf yaitu: tanpa pemangkasan $(\mathrm{P} 1)$, pemangkasan $10 \mathrm{~cm}(\mathrm{P} 2)$, pemangkasan $15 \mathrm{~cm}(\mathrm{P} 3),(2)$. Pemberian dosis pupuk Azolla pinnata (A) yang terdiri dari 4 taraf yaitu : tanpa pemberian dosis pupuk azolla (A0) pemberian dosis pupuk kompos azolla 5 gram (A1), pemberian dosis pupuk kompos azolla 10 gram ( A2 ), pemberian dosis pupuk kompos azolla 15 gram (A3), Kedua faktor perlakuan tersebut dikombinasikan sehinngga diperoleh 12 kombinasi perlakuan. Data dianalisis menggunakan Analisis Ragam, yang dilanjutkan dengan Uji Beda Nyata Terkecil pada taraf $5 \%$. Hasil penelitian menunjukkan perlakuan pemangkasan pucuk dan pemberian dosis pupuk kompos Azolla pinnata berpengaruh nyata terhadap komponen pertumbuhan yaitu jumlah daun pada perlakuan (A2P1) dengan rata - rata jumlah daun 414 helai dan berat brangkasan basah (A2P1) dengan berat rata- rata 1915,33 gram, sedangkan pada hasil tanaman ubi jalar ungu berpengaruh nyata pada jumlah umbi yaitu pada perlakuan (A3P1) dengan rata rata jumlah umbi 13,67 buah .
\end{abstract}

Kata Kunci : Azolla pinnata, Pemangkasan pucuk, Pertumbuhan dan Hasil, Ubi Jalar Ungu

\begin{abstract}
Research on "The effect of shoot trimming and the administration of Azolla pinnata compost (Ipomea batatas blackie.)" Has been carried out from 12 October 2018 to 18 January 2019 Randusari RT 02 RW 01, Slogohimo, Wonogiri. This study aims to (1) determine the effect of shoot trimming on the growth and yield of purple sweet potato (Ipomoea batatas blackie.), (2) to determine the effect of dosing Azolla pinnata compost on the growth and yield of sweet potatoes (Ipomoea batatas blackie.), (3) find out the best effect of shoot trimming and the administration of Azolla pinnata compost dosage on the growth and yield of purple sweet potato (Ipomoea batatas blackie.) The study used a Complete Randomized Block Design (RAKL) arranged factorially. The treatment consisted of 2 factors, each treatment combination was repeated 3 times. The two factors are: (1) shoot trimming $(P)$ with 3 (three) levels, namely: without pruning (P1), pruning $10 \mathrm{~cm}(P 2)$, trimming $15 \mathrm{~cm}(P 3),(2)$. Giving doses of Azolla pinnata fertilizer (A) which consists of 4 levels, namely: without dosing azolla fertilizer (AO) giving doses of azolla compost fertilizer 5 grams (A1), giving a dose of 10 grams of azolla
\end{abstract}


compost fertilizer (A2), dosing azolla compost fertilizer 15 grams (A3), the two treatment factors were combined so that 12 combinations of treatments were obtained. Data were analyzed using Variety Analysis, followed by the Smallest Significant Difference Test at the level of 5\%. The results showed the treatment of shoot trimming and the administration of Azolla pinnata compost dosage significantly affected the growth component, namely the number of leaves in the treatment (A2P1) with an average number of 414 leaf strands and wet stover weight (A2P1) with an average weight of 1915.33 grams while the results of the purple sweet potato plant significantly affected the number of tubers, namely the treatment (A3P1) with an average number of tubers of 13.67 fruit.

Keywords: Azolla pinnata, shoot trimming, growth and yield, purple sweet potato

\section{PENDAHULUAN}

Ubi jalar merupakan tanaman yang sangat familiar bagi masyarakat. Dalam masyarakat dikenal ada beberapa jenis ubi jalar. Jenis yang paling umum adalah ubi jalar putih, merah, ungu,kuning atau orange. Kelebihan dari ubi jalar yang berwarna yaitu mengandung antioksidan yang kuat untuk menetralisir keganasan radikal bebas penyebab penuaan dini dan pencetus aneka penyakit degeneratif seperti kanker dan jantung. Zat gizi lain yang banyak terdapat dalam ubi jalar adalah energi,vitamin $\mathrm{C}$, vitamin B6 ( piridoksin) yang berperan penting dalam kekebalan tubuh. Kandungan mineralnya dalam ubi jalar seperti fosfor, kalsium, mangan,zat besi dan serat yang larut untuk menyerap kelebihan lemak/kolesterol dalam darah (Reifa, 2005).

Dengan adanya diversifikasi ubi jalar terutama ubi jalar ungu yang mempunyai berbagai kandungan yang lebih tinggi dibandingkan dengan ubi jalar putih maupun ubi jalar orange diharapkan akan meningkatkan nilai ekonomi dan memper panjang daya simpannya selain sebagai bahan baku industri pengolahan pangan. Salah satu bentuk diversifikasinya yaitu tepung ubi jalar ungu. Tepung ubi jalar merupakan hancuran ubi jalar yang dihilangkan sebagian kadar airnya sekitar 7 $\%$ (Sarwono, 2005). Pemangkasan merupakan faktor-faktor yang perlu diteliti untuk mendapatkan teknologi produksi benih bermutu.

Pemberian kompos Azolla pinnata memiliki banyak keunggulan, kompos ini mudah dibuat dan mengandung unsur hara yang tinggi. Komposisi unsur hara pada kompos Azolla pinnata adalah sebagai berikut: $0,30 \% \mathrm{P}, 0,65 \% \mathrm{~K}, 15,1 \% \mathrm{C}$ organik, 3,91\% N-total, nilai $\mathrm{C} / \mathrm{N} 10$ dan $39,9 \%$ bahan organik (Putri, 2013).

\section{METODE PENELITIAN}

Penelitian yang dilakukan adalah menggunakan perancangan dasar Rancangan Acak Lengkap (RAKL) yang disusun secara faktorial, terdiri dari dua faktor perlakuan yaitu pemangkasan pucuk dan pemberian pupuk kompos azolla pinnata, terdapat 12 kombinasi dan masing-masing kombinasi diulang sebanyak 3 kali sehingga ada 36 petak. Adapun faktor-faktornya sebagai berikut:

Faktor 1 pemangkasan pucuk (P) yang terdiri dari 3 macam antara lain :

$\mathrm{P}_{1}$ : Tanpa pemangkasan pucuk

$\mathrm{P}_{2}$ : Dengan pemangkasan pucuk $10 \mathrm{~cm}$

$\mathrm{P}_{3}$ : Dengan pemangkasan pucuk $15 \mathrm{~cm}$

Faktor 2 menggunakan dosis Azolla pinnata (A) yang terdiri dari 4 macam antara lain :

$\mathrm{A}_{0}$ : Tanpa azolla pinnata

$\mathrm{A}_{1}$ : menggunakan azolla pinnata $5 \mathrm{gr}$

$\mathrm{A}_{2}$ : menggunakan azolla pinnata $10 \mathrm{gr}$

$\mathrm{A}_{3}$ : menggunakan azolla pinnata $15 \mathrm{gr}$

Sehingga seluruhnya diperoleh 12

kombinasi perlakuan dan masing-masing perlakuan diulang sebanyak tiga kali yaitu sebagai berikut:

$\mathrm{A}_{0} \mathrm{P}_{1}$ : Tanpa menggunakan azolla pinnata dan tanpa pemangkasan pucuk

$\mathrm{A}_{0} \mathrm{P}_{2}$ : Tanpa menggunakan azolla pinnata dan dengan pemangkasan pucuk $10 \mathrm{~cm}$

$\mathrm{A}_{0} \mathrm{P}_{3}$ : Tanpa menggunakan azolla pinnata dan dengan pemangkasan pucuk $15 \mathrm{~cm}$

$\mathrm{A}_{1} \mathrm{P}_{1}$ : Menggunakan azolla pinnata $5 \mathrm{gr}$ dan tanpa pemangkasan pucuk

$\mathrm{A}_{1} \mathrm{P}_{2}$ : Menggunakan azolla pinnata $5 \mathrm{gr}$ dan dengan pemangkasan pucuk $10 \mathrm{~cm}$

$\mathrm{A}_{1} \mathrm{P}_{3}$ : Menggunakan azolla pinnata $5 \mathrm{gr}$ dan dengan pemangkasan pucuk $15 \mathrm{~cm}$

$\mathrm{A}_{2} \mathrm{P}_{1}$ : Menggunakan azolla pinnata $10 \mathrm{gr}$ dan tanpa pemangkasan pucuk 
$\mathrm{A}_{2} \mathrm{P}_{2}$ : Menggunakan azolla pinnata $10 \mathrm{gr}$ dan dengan pemangkasan pucuk $10 \mathrm{~cm}$

$\mathrm{A}_{1} \mathrm{P}_{3}$ : Menggunakan azolla pinnata $10 \mathrm{gr}$ dan dengan pemangkasan pucuk $15 \mathrm{~cm}$

$\mathrm{A}_{3} \mathrm{P}_{1}$ : Menggunakan azolla pinnata $15 \mathrm{gr}$ dan tanpa pemangkasan pucuk

$\mathrm{A}_{3} \mathrm{P}_{2}$ : Menggunakan azolla pinnata $15 \mathrm{gr}$ dan dengan pemangkasan pucuk $10 \mathrm{~cm}$

$\mathrm{A}_{3} \mathrm{P}_{3}$ : Menggunakan azolla pinnata $15 \mathrm{gr}$ dan dengan pemangkasan pucuk $15 \mathrm{~cm}$

\section{HASIL}

Hasil dari penelitian pengaruh pemangkasan pucuk dan pemberian dosis pupuk Azolla pinnata terhadap pertumbuhan dan hasil ubi jalar ungu (Ipomoea batatas blackie) terdapat pada tabel I dan tabel II

Tabel I. Pengaruh Pemangkasan Pucuk dan

\begin{tabular}{ccc}
\hline Perlakuan & $\begin{array}{c}\text { Jumlah Umbi } \\
\text { (buah) }\end{array}$ & $\begin{array}{c}\text { Berat Umbi } \\
\text { (gram })\end{array}$ \\
\hline A0P1 & $9,33 \mathrm{~b}$ & $736,67 \mathrm{a}$ \\
A0P2 & $9,67 \mathrm{~b}$ & $638,33 \mathrm{a}$ \\
A0P3 & $10,33 \mathrm{~b}$ & $586,33 \mathrm{a}$ \\
A1P1 & $8,33 \mathrm{~b}$ & $350,00 \mathrm{a}$ \\
A1P2 & $8,67 \mathrm{~b}$ & $424,33 \mathrm{a}$ \\
A1P3 & $12,33 \mathrm{c}$ & $435,00 \mathrm{a}$ \\
A2P1 & $6,33 \mathrm{~b}$ & $418,67 \mathrm{a}$ \\
A2P2 & $2,67 \mathrm{a}$ & $312,67 \mathrm{a}$ \\
A2P3 & $10,00 \mathrm{~b}$ & $447,33 \mathrm{a}$ \\
A3P1 & $13,67 \mathrm{c}$ & $435,00 \mathrm{a}$ \\
A3P2 & $7,00 \mathrm{~b}$ & $280,00 \mathrm{a}$ \\
A3P3 & $6,67 \mathrm{~b}$ & $321,33 \mathrm{a}$ \\
\hline
\end{tabular}

Pemberian Dosis Pupuk Azolla pinnata Terhadap Pertumbuhan Ubi Jalar Ungu ( Ipomoea batatas blackie ).

Tabel II. Pengaruh Pemangkasan Pucuk dan Pemberian Dosis Pupuk Azolla pinnata Terhadap Pertumbuhan Ubi Jalar Ungu ( Ipomoea batatas blackie ).

\begin{tabular}{cccc}
\hline Perlakuan & $\begin{array}{c}\text { Jumlah } \\
\text { Daun } \\
\text { (helai) }\end{array}$ & $\begin{array}{c}\text { Panjang } \\
\text { Sulur }(\mathrm{cm})\end{array}$ & $\begin{array}{c}\text { Berat } \\
\text { Brangkasan } \\
\text { Basah } \\
\text { (gram) }\end{array}$ \\
\hline A0P1 & 359 b & $163,67 \mathrm{a}$ & $1689,33 \mathrm{~b}$ \\
A0P2 & $370 \mathrm{~b}$ & $183,33 \mathrm{a}$ & $1131,67 \mathrm{~b}$ \\
A0P3 & $392 \mathrm{~b}$ & $185,00 \mathrm{a}$ & $1262,67 \mathrm{~b}$ \\
A1P1 & $384 \mathrm{~b}$ & $169,67 \mathrm{a}$ & $1265,00 \mathrm{~b}$ \\
A1P2 & $351 \mathrm{~b}$ & $178,33 \mathrm{a}$ & $1283,33 \mathrm{~b}$ \\
A1P3 & $294 \mathrm{a}$ & $179,33 \mathrm{a}$ & $1240,00 \mathrm{~b}$ \\
A2P1 & $414 \mathrm{~b}$ & $180,67 \mathrm{a}$ & $1915,33 \mathrm{~b}$ \\
A2P2 & $344 \mathrm{~b}$ & $182,33 \mathrm{a}$ & $1279,33 \mathrm{~b}$ \\
A2P3 & $345 \mathrm{~b}$ & $192,67 \mathrm{a}$ & $1489,33 \mathrm{~b}$ \\
A3P1 & $339 \mathrm{~b}$ & $158,33 \mathrm{a}$ & $797,33 \mathrm{a}$ \\
A3P2 & $399 \mathrm{~b}$ & $199,67 \mathrm{a}$ & $1673,00 \mathrm{~b}$ \\
A3P3 & $389 \mathrm{~b}$ & $152,33 \mathrm{a}$ & $1227,33 \mathrm{~b}$ \\
\hline
\end{tabular}

Perlakuan pemangkasan pucuk dan pemberian dosis pupuk kompos Azolla berpengaruh nyata terhadap komponen pertumbuhan yaitu jumlah daun pada perlakuan (A2P1) dengan rata - rata jumlah daun 414 helai dan berat brangkasan basah (A2P1) dengan berat rata- rata 1915,33 gram, dan tidak berpengaruh nyata terhadap perlakuan panjang sulur. Perlakuan pemangkasan pucuk dan pemberian dosis pupuk kompos Azolla berpengaruh nyata terhadap komponen hasil tanaman yaitu . jumlah umbi yaitu pada perlakuan (A3P1) dengan rata - rata jumlah umbi 13,67 buah, namun tidak berpengaruh nyata terhadap perlakuan berat umbi.

\section{PEMBAHASAN}

1. Pengaruh pemangkasan pucuk dan pemberian dosis pupuk kompos Azolla pinnata terhadap pertumbuhan dan hasil tanaman ubi jalar ungu ungu.

Berdasarkan hasil penelitian tersebut diketahuai bahwa perlakuan pemangkasan pucuk dan pemberian dosis pupuk kompos Azolla pinnataberpengaruh nyata terhadap komponen pertumbuhan jumlah daun sebagaimana terlihat pada gambar 2 sedangkan pada panjang sulur dan berat brangkasan basah tidak berpengaruh nyata sebagaimana terlihat pada gambar 3 dan 4 .

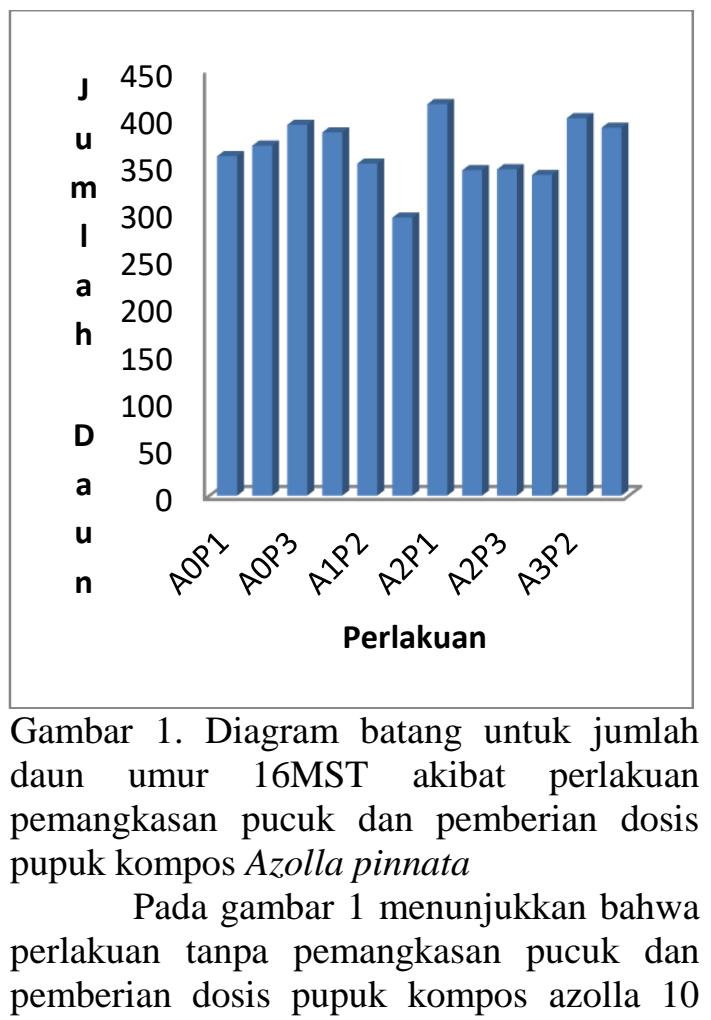


gram (A2P1) meningkatkan pertumbuhan jumlah daun tanaman ubi jalar ungu dengan jumlah daun rata-rata 414 helai di bandingkan perlakuan yang lainnya hal ini diduga karena, pemangkasan pucuk pada tanaman ubi jalar ungu menghentikan dominansi apikal sehingga pertumbuhan panjang batang lebih lambat dan juga pertumbuhan daun. Penelitian yang dilakukan oleh Munawaroh dan Aziz (2014) menjelaskan bahwa perlakuan pemangkasan pada tanaman torbangun dapat menghambat pertambahan tinggi tanaman.dan diduga bahwa ketersediaan unsur hara $\mathrm{N}$ yang terdapat di dalam tanah sudh tercukupi hal ini sesuai dengan pendapat Sarief (1986) yang menyatakan bahwa pengaruh penambahan pupuk terhadap tanah adalah untuk fase pertumbuhan agar maksimal dan menciptakan suatu kadar zat hara yang tinggi, namun tidak terlalu berpengaruh terhadap peningkatan produksi dan kualitas tanaman

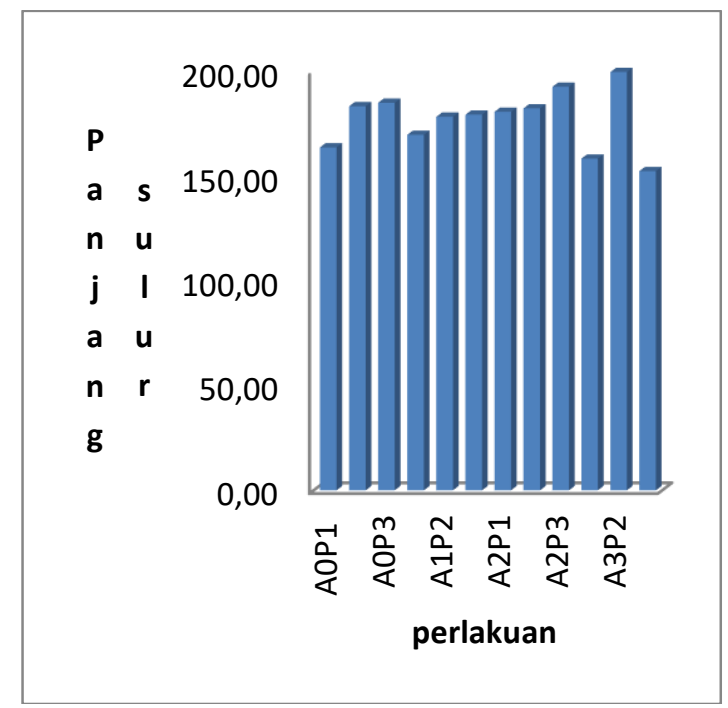

Gambar 2. Diagram batang untuk panjang sulur umur 16MST akibat perlakuan pemangkasan pucuk dan pemberian dosis pupuk kompos Azolla pinnata

Gambar 2. Menunjukkan bahwa perlakuan pemangkasan pucuk $10 \mathrm{~cm}$ dan pemberian dosis pupuk kompos Azolla 15 gram (A3P2) tidak berpengaruh terhadap pertumbuhan jumlah daun tanaman ubi jalar ungu dengan perlakuan pemangkasan pucuk $15 \mathrm{~cm}$ dan pemberian dosis pupuk kompos Azolla 15 gram (A3P3) hal ini diduga , pemangkasan pucuk pada tanaman ubi jalar ungu menghentikan dominansi apikal sehingga pertumbuhan panjang batang lebih lambat dan juga pertumbuhan daun dan juga pertumbuhan daun dan pada pembuatan pupuk kompos Azolla tidak dikeringkan melainkan Azolla basah langsung difermentasi atau dibuat kompos hal ini membuat Azolla tidak menjadi kompos melainkan akan busuk dan mengandung racun bagi tanaman yang dapat menghambat pertumbuhan dan hasil tanaman ubi jalar ungu seperti yang dijelaskan pada penelitian Yulipriyanto (2010), . proses pengomposan Azolla pinnata dimulai dengan mencuci Azolla pinnata hingga bersih kemudian ditiriskan dan dikeringanginkan selama 24 jam. Setelah itu Azolla pinnata dikeringkan lagi dengan oven pada suhu $50^{\circ} \mathrm{C}$ sampai kadar air Azolla pinnata berkurang 50\%. Penelitian yang dilakukan oleh Munawaroh dan Aziz (2014) menjelaskan bahwa perlakuan pemangkasan menghambat pertumbuhan tinggi tanaman pada tanaman Torbangun yang sudah berbeda spesies dengan tanaman ubi jalar ungu ungu, dan juga diduga pemangkasan $10 \mathrm{~cm}$ dan $15 \mathrm{~cm}$ kurang panjang karena pertumbuhan panjang sulur pada ubi jalar ungu sangat cepat ditanah yang subur sesuai dengan pendapat I Wayan Jedeng (2011). dan diduga bahwa ketersediaan unsur hara $\mathrm{N}$ yang terdapat di dalam tanah sudh tercukupi hal ini sesuai dengan pendapat Sarief (1986) yang menyatakan bahwa pengaruh penambahan pupuk terhadap tanah adalah untuk fase pertumbuhan agar maksimal dan menciptakan suatu kadar zat hara yang tinggi, namun tidak terlalu berpengaruh terhadap peningkatan produksi dan kualitas tanaman.

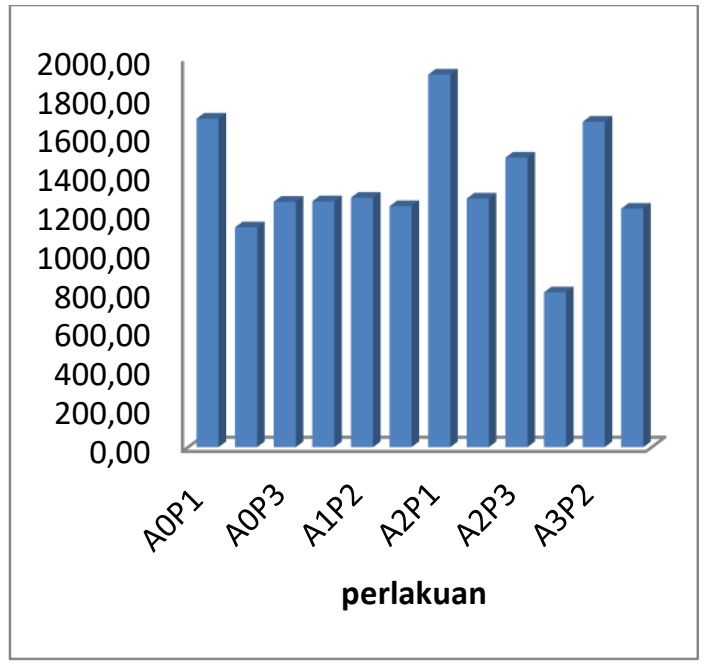


Gambar 3. Diagram batang untuk berat brangkasan basah umur 16MST akibat perlakuan pemangkasan pucuk dan pemberian dosis pupuk kompos azolla

Gambar 3. menunjukkan bahwa perlakuan tanpa pemangkasan pucuk dan pemberian dosis pupuk kompos Azolla 10 gram (A2P1) dengan rata-rata berat brangkasan basah 1915,33 gram meningkatkan pertumbuhan jumlah daun tanaman ubi jalar ungu di bandingkan perlakuan yang lainnya hal ini diduga karena, pemangkasan pucuk pada tanaman ubi jalar ungu menghentikan dominansi apikal sehingga pertumbuhan panjang batang lebih lambat dan juga pertumbuhan daun. Penelitian yang dilakukan oleh Munawaroh dan Aziz (2014) menjelaskan bahwa perlakuan pemangkasan pada tanaman Torbangun dapat menghambat pertambahan tinggi tanaman.dan diduga bahwa ketersediaan unsur hara $\mathrm{N}$ yang terdapat di dalam tanah sudh tercukupi hal ini sesuai dengan pendapat Sarief (1986) yang menyatakan bahwa pengaruh penambahan pupuk terhadap tanah adalah untuk fase pertumbuhan agar maksimal dan menciptakan suatu kadar zat hara yang tinggi, namun tidak terlalu berpengaruh terhadap peningkatan produksi dan kualitas tanaman.

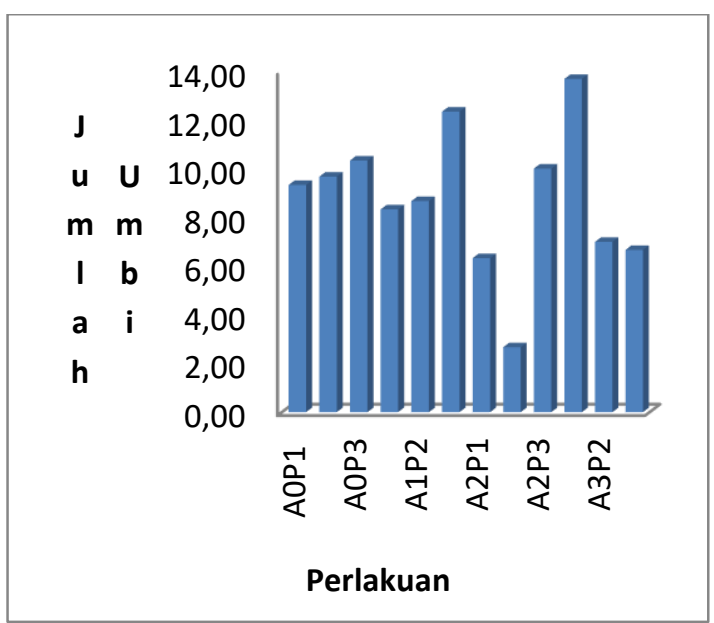

Gambar 4. Diagram batang untuk jumlah umbi umur 16MST akibat perlakuan pengaruh pemangkasan pucuk dan pemberian dosis pupuk kompos azolla pinata

Gambar 4. menunjukkan bahwa perlakuan tanpa pemangkasan pucuk dan pemberian dosis pupuk kompos azolla 15 gram (A3P1) dengan jumlah umbi rata-rata
13,67 buah meningkatkan jumlah umbi tanaman ubi jalar ungu di bandingkan perlakuan yang lainnya hal ini diduga karena, pemangkasan pucuk pada tanaman ubi jalar ungu menghentikan dominansi apikal sehingga pertumbuhan panjang batang lebih lambat dan juga pertumbuhan daun. Penelitian yang dilakukan oleh Munawaroh dan Aziz (2014) menjelaskan bahwa perlakuan pemangkasan pada tanaman torbangun dapat menghambat pertambahan tinggi tanaman.

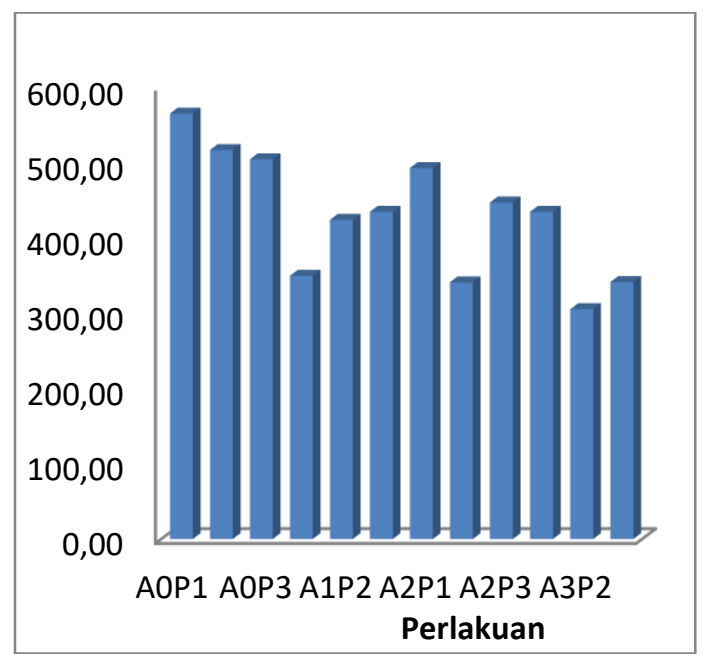

Gambar 5. Diagram batang untuk berat umbi umur 16MST akibat perlakuan pengaruh pemangkasan pucuk dan pemberian dosis pupuk kompos azolla pinata

Gambar 5. menunjukkan bahwa perlakuan tanpa pemangkasan pucuk dan tanpa pemberian dosis pupuk kompos azolla (A0P1) dengan berat umbi rata-rata 565,33 gram tidak berpengaruh terhadap hasil berat umbi tanaman ubi jalar ungu dengan perlakuan pemangkasan pucuk $15 \mathrm{~cm}$ dan pemberian dosis pupuk kompos azolla 15 gram dengan berat rata-rata umbi 341,67 gram hal ini diduga karena pemangkasan pucuk pada tanaman ubi jalar ungu menghentikan dominansi apikal sehingga pertumbuhan panjang batang lebih lambat dan juga pertumbuhan daun dan pada pembuatan pupuk kompos Azolla tidak dikeringkan melainkan Azolla basah langsung difermentasi atau dibuat kompos hal ini membuat Azolla tidak menjadi kompos melainkan akan busuk dan mengandung racun bagi tanaman yang dapat menghambat pertumbuhan dan hasil tanaman ubi jalar ungu seperti yang dijelaskan pada penelitian Yulipriyanto 
(2010),. proses pengomposan Azolla pinnata dimulai dengan mencuci Azolla pinnata hingga bersih kemudian ditiriskan dan dikeringanginkan selama $24 \mathrm{jam}$. Setelah itu Azolla pinnata dikeringkan lagi dengan oven pada suhu $50^{\circ} \mathrm{C}$ sampai kadar air Azolla pinnata berkurang 50\%. Penelitian yang dilakukan oleh Munawaroh dan Aziz (2014) menjelaskan bahwa perlakuan pemangkasan pada tanaman torbangun dapat menghambat pertambahan tinggi tanaman.dan diduga bahwa ketersediaan unsur hara $\mathrm{N}$ yang terdapat di dalam tanah sudah tercukupi hal ini sesuai dengan pendapat Sarief (1986) yang menyatakan bahwa pengaruh penambahan pupuk terhadap tanah adalah untuk fase pertumbuhan agar maksimal dan menciptakan suatu kadar zat hara yang tinggi, namun tidak terlalu berpengaruh terhadap peningkatan produksi dan kualitas tanaman.

\section{KESIMPULAN DAN SARAN}

\section{A. Kesimpulan}

1. Perlakuan pemangkasan pucuk dan pemberian dosis pupuk kompos Azolla berpengaruh nyata terhadap komponen pertumbuhan yaitu jumlah daun pada perlakuan (A2P1) dengan rata - rata jumlah daun 414 helai dan berat brangkasan basah (A2P1) dengan berat rata- rata 1915,33 gram, dan tidak berpengaruh nyata terhadap perlakuan panjang sulur.

2. Perlakuan pemangkasan pucuk dan pemberian dosis pupuk kompos Azolla berpengaruh nyata terhadap komponen hasil tanaman yaitu . jumlah umbi yaitu pada perlakuan (A3P1) dengan rata rata jumlah umbi 13,67 buah, namun tidak berpengaruh nyata terhadap perlakuan berat umbi.

3. Perlakuan terbaik adalah perlakuan tanpa pemangkasan pucuk dan pemberian dosis pupuk kompos Azolla 10 gram(A2P1) yaitu pada jumlah daun dan berat brangkasan basah, dengan rata - rata jumlah daun 414 helai dan rata - rata brangkasan basah 1915,33 gram, dan juga pada perlakuan tanpa pemangkasan pucuk dan pemberian dosis pupuk kompos Azolla 15 gram (A3P1) yaitu pada jumlah umbi dengan rata - rata 13,67 buah.

\section{B. Saran}

Berdasarkan penelitian di atas maka untuk mendapatkan pertumbuhan dan hasil terbaik pada tanaman ubi jalar ungu sebaiknya mengunakan perlakuan pemangkasan dan pemberian dosis pupuk kompos Azolla yang sesuai dengan kebutuhan tanaman.

\section{DAFTAR PUSTAKA}

Amir Lukman. 2012. Ketersediaan Nitrogen Tanah dan Pertumbuhan Tanaman Bayam (Amaranthus tricolor L.) yang Diperlakukan dengan Pemberian Pupuk Kompos Azolla. Jurusan Biologi Fakultas Matematika dan Ilmu Pengetahuan Alam Universitas Negeri Makassar.

Anggraini F., Suranto A. dan Aini N. 2013. Sistem tanam dan umur bibit pada tanaman padisawah (Oryza sativa L.) varietas inpari 13. Jurnal Produksi

Tanaman 1(2):52-60.

[Balitbangtan] Balai Penelitian dan Pengembangan Pertanian. 2001. Cilembu.

http://pangan.litbang.pertanian.go.id/v arietas-137.html [12 Mei 2016].

BPS. 2018. Statistik Indonesia 2007 (Produksi Umbi-umbian di Indonesia). Jakarta.

Dewi, A. I. R. 2007. Fiksasi N Biologis Pada Ekosistem Tropis. Program Pasca Sarjana Universitas Padjadjaran Bandung. Hlm 37-38.

Djojosuwito, S. 2010. Azolla. Pertanian Organik dan multigna. J. Kanisius. Yogyakarta. 39(22):11-36

Ferlina, Shinta. 2010. Khasiat Ubi Jalar Ungu.

http://www.khasiatku.com/ubijalarungu/ (diakses tanggal 22 Januari 2010). Bogor

Gunawan Iwan, 2012. Substitusi Kebutuhan Nitrogen Tanaman Padi Sawah oleh Tumbuhan Air Azolla (Azolla pinnata).Lampung

Husna Nugrahapraja, 2008. Pertumbuhan Tanaman Air Azolla pinnata $R$. Br. (Mata Lele) pada Medium 
Pertumbuhan Berbeda. Skripsi (2008), Program Studi Sarjana Biologi SITH. ITB Bandung.

Januwati M, Pitono J. dan Ngadimin. 1996. Pengaruh pemangkasan terhadap

pertumbuhan dan produksiterna tanaman sambiloto. Balai Penelitian

Tanaman Rernpah dan Obat, Bogor 3(1):2021.

Juanda D. dan Cahyono B. 2000. Budidaya dan Analisis Usahatani Ubi Jalar. Kanisius, Yogyakarta.

Kolam Azolla. 2008. Beberapa hasil penelitian tentang azolla. http://kolamazolla.blogspot.com/2009 /10/penelitian-azolla-di-fapertaugm.html

Kumalaningsih, Sri. 2006. Antioksidan Alami. Trubus Agrisarana. Surabaya

La Karimuna, Safitri dan Sabaruddin L.O. 2009. Pengaruh jarak tanam dan

pemangkasan terhadap kualitas silase dua varietas jagung (Zea mays L.).Agripet vol 9(1).

Maftuchah dan Winaya, A. 2000. Komposisi Media Tumbuh Untuk Asosiasi Azolla-Anabaena azollae. Vol.7, No.1, Hal 1-5. Pusat Bioteknologi Pertanian, Universitas Muhammadiyah Malang.

Neliyati, 2005. Pertumbuhan dan Hasil Tanaman Tomat pada Beberapa Dosis Kompos Sampah Kota. Jurnal Agronomi. 10 (2) : 93 - 97.

Onwueme,F.C. 1978. The Tropical Tuber Crops, Yams, Cassava, Sweetpotato and Coco Yams. John Wiley and Sons. Chichester. New York.

Panggabean F.DM., Mawami L. dan Nissa T.C. 2014. Respon pertumbuhan danproduksi bengkuang (Pachyrhizus erosus (L.) Urban) terhadap waktupemangkasan dan jarak tanam. Jurnal Agroekologi 2(2):702-711.

Putri, F. P., Husni T. S., Titin S. 2013. Pengaruh Pupuk N, P, K, Azolla pinnata (Azolla pinnata Pinnata) dan Kayu Apu (Pistia Stratiotes) pada
Pertumbuhan dan Hasil Padi Sawah (Oryza sativa). Jurnal Produksi Tanaman. 1 (3) : 1 - 13.

Rao, S. 2007. Mikroorganisme Tanah dan Pertumbuhan Tanaman Menggunakan Pupuk Kompos Azolla pinnata. Penerbit Universitas Indonesia. Jakarta.

Reifa. 2005. Ubi Jalar Sehatkan Mata dan Jantung, serta Mencegah Kanker.Majalah Kartini Nomor: 2134 Hal.148.

Rodriquez,P., B.L. Raina, E.B. Pantastico dan M.B. Batti. 1986. Mutu Buahbuahan Mentah untuk Pengolahan. hlm.750-810. Dalam E.B. Pantastico (Ed.). Diterjemahkan Kamariyani. Fisiologi Lepas Panen. Gadjah Mada Univ. Press. Yogyakarta.

Saraswati R, Setyorini D, Hartatik. W. 2011. Pupuk Organik Dan Pupuk Hayati Organic Fertilizer And Biofertilizer dengan Azolla pinnata. Balai Besar Penelitian Dan Pengembangan Sumberdaya Lahan Pertanian. Bogor.

Sarwono, B. 2005. Ubi Jalar. Penebar Swadaya. Jakarta.

Setyorini, D., R. Saraswati dan E. K. Anwar. 2006. 2. Kompos. Badan Penelitian dan Pengembangan Pertanian, Indonesia. Online; (Diakses tanggal 3 Agustus 2012).

Srirejeki D.I., Maghfoer M.D. dan Herlina N. 2015. Aplikasi PGPR dan dekamon

serta pemangkasan pucuk untuk meningkatkan produktivitas tanaman buncis

(Phaseolus vulgaris L.) tipe tegak. Jurnal Produksi Tanaman 3(4):302-310.

Suarsana, M. 2011. Habitat dan Niche Paku Air Tawar (Azolla pinnata Linn.) (Suatu Kajian Komponen Penyusun Ekosistem). Vol.11, No. 2. Fakultas Pertanian UNIPAS Singaraja. Medan

Suharsi T.K., Surahman M. dan Rahmatani S.F. 2013. Pengaruh jarak tanam danpemangkasan tanaman pada produksi dan mutu benih koro 
pedang(Canavalia enziformis). Jurnal Ilmu Pertanian Indonesia 18 (3):172177.

Suismono. 2001. Teknologi Pembuatan Tepung dan Pati Ubi-Ubian untukMenunjamg Ketahanan Pangan. Majalah pangan nomor: 37/X/Juli/2001Hal. 37-49.

Suparman. 2007. Bercocok tanam ubi jalar. Azka Press

Suriadikarta, D. A., T. Prihatini, D. Setyorini dan W. Hartatik. 2005. Teknologi Pengelolaan Bahan Organik Tanah. Pusat Penelitian dan Pengembangan Tanah dan Agroklimat. Badan Penelitian dan Pengembangan Pertanian Departemen Pertanian. Jakarta

Usman I.R. dan Aziz A. 2013. Analisis pertumbuhan dan produksi kacang koro

pedang (Canavalia enziformis) pada berbagai konsentrasi pupuk organik cair

dan pemangkasan. Jurnal Galung Tropika 2(2):85-96.

Winarno, F.G. dan Laksmi. 1973. Pigmen dalam Pengolahan Pangan. Departemen Teknologi Hasil Pertanian. Fakultas Teknologi Pangan dan Mekanisasi Pertanian IPB Bogor. Bogor:22-23.

Yetti H. dan Ardian. 2010, Pengaruh penggunaan jarak tanam terhadap

pertumbuhan dan produksi padi sawah (Oryza Sativa L.) varietas IR 42

dengan metode SRI. SAGU 9(1):21-27.

Yulipriyanto H. 2010. Biologi Tanah Dan Strategi Pengelolaannya. Graha Ilmu. Yogyakarta.

Yuwono, M, Nur B dan Lily A. 2010. Pertumbuhan Dan Hasil Ubijalar (IpomoeaBatatas (L.) Lam.) Pada Macam Dan Dosis Pupuk Organik Yang BerbedaTerhadap Pupuk Anorganik. http://images.soemarno.multiply.multi plycontent.com/ diakses tanggal 22januari 2010. 